\title{
Effects of pair versus single housing on performance and behavior of dairy calves before and after weaning from milk
}

\author{
A. De Paula Vieira, M. A. G. von Keyserlingk, and D. M. Weary ${ }^{1}$ \\ Animal Welfare Program, University of British Columbia, 2357 Main Mall, Vancouver, BC, V6T 1Z4, Canada
}

\section{ABSTRACT}

This experiment tested the effects of pair versus single housing on the performance and behavior of dairy calves before and after weaning. Twenty-seven Holstein calves were separated from the dam within 6 $\mathrm{h}$ of birth, housed in individual pens for $4 \mathrm{~d}$, and then assigned to either continued individual housing ( $\mathrm{n}=$ 9 calves) or pair housing ( $\mathrm{n}=9$ pairs). Calves had ad libitum access to starter, hay, and water via buckets. Pasteurized whole milk was fed via teat twice a day for $2 \mathrm{~h}$ at ad libitum volumes until d 36. During the milkfeeding period, paired calves showed higher intakes of starter than did the individually housed calves (averaging 93 vs. $59 \pm 11 \mathrm{~g} / \mathrm{d}$ per calf). Calves were weaned from milk from d 37 to 41 by progressive dilution of milk with water, and the teat was removed on d 49 . Calves in both treatments vocalized in response to teat removal but this response was less in paired calves than in individually housed calves (84 vs. $194 \pm 12$ calls/2-h period per calf on d 49). On d 56, calves were moved to group pens, mixed with other calves, and observed for 15 d. Starter, water, and hay were available ad libitum via automatic feeders. Compared with calves previously housed in single pens, paired calves had a shorter latency to start feeding $(9.1 \pm 2.6$ vs. $49.5 \pm 4.1 \mathrm{~h} /$ calf $)$, visited the starter feeder more frequently $(41.6 \pm 3.0$ vs. $26.4 \pm 3.3$ visits $/ \mathrm{d}$ per calf), spent more time at the feeder $(87.8 \pm 2.5$ vs. $65.3 \pm 2.9 \mathrm{~min} / \mathrm{d}$ per calf $)$, and consumed more starter (3.4 vs. $2.3 \pm 0.2 \mathrm{~kg} / \mathrm{d}$ per calf). Weight gains at mixing were higher for paired than for individually housed calves on $\mathrm{d} 2$ and 3 after mixing ( 0.5 vs. $-2.4 \pm 0.3 \mathrm{~kg} / \mathrm{d}$ per calf; and 0.8 vs. $-0.9 \pm 0.3$ $\mathrm{kg} / \mathrm{d}$ per calf, respectively). The results indicate that pair housing during the milk-feeding stage reduces calf responses to weaning and improves performance after weaning when calves are housed in groups.

Key words: group housing, performance, behavior, welfare

Received June 25, 2009.

Accepted February 22, 2010.

${ }^{1}$ Corresponding author: danweary@interchange.ubc.ca
INTRODUCTION

Dairy calves are typically separated from the cow soon after birth and housed in individual pens or hutches. Little is known about how dairy calves might benefit from social housing. Work on laboratory animals has shown that during stressful events animals are often attracted to a social partner (Davitz and Mason, 1955; Morrison and Hill, 1967; Taylor, 1981), and that social interactions result in positive neurochemical signals during times of stress (Panksepp, 1998). Benefits of group housing on health and behavior have also been reported (e.g., improved immune function, lower stress-like cardiovascular responses, and more time spent sleeping; Sharp et al., 2002; Bartolomucci, 2007), suggesting that grouping dairy calves during the milkfeeding phase may also provide benefits.

Previous work has shown that dairy heifers are less fearful when tested in the presence of a familiar social partner (Jensen et al., 1997, 1999; Færevik et al., 2007). The lack of social partners early in life has been reported to delay exploratory behavior (Jensen et al., 1997). Veissier et al. (1994) showed that individually housed calves had reduced ability to cope with unfamiliar animals during initial encounters at mixing. Moreover, within $2 \mathrm{~h}$ after mixing, individually housed calves showed increased aggression and reduced play and grooming compared with group-housed calves.

One stressor faced by every dairy calf is weaning from milk to a solid diet. In response to weaning, calves show increased activity and vocalizations combined with a period of growth check (Weary et al., 2008). Chua et al. (2002) reported that calves that had been paired showed less of a growth check at weaning than did individually housed calves. To our knowledge, no research has investigated the effects of early social housing on the behavioral responses of dairy calves to weaning.

Several studies have reported increased weight gains for group-housed dairy calves compared with individually housed calves during the milk feeding and weaning periods (e.g., Chua et al., 2002; Xicatto et al., 2002; Tapki, 2007), although some other studies have reported no effect (Færevik et al., 2007) or even increased weight gains for singly housed calves (e.g., Terré et al., 2006). 
The higher weight gain for calves housed in groups is often attributed to social facilitation of feeding, an effect reported in many farm species (see Hsia and WoodGush, 1984; Napolitano et al., 2003; Wattanakul et al., 2005). The variability among studies may relate to differences in management (e.g., the number of animals per group, milk volume provided, duration of the feeding period, and weaning method).

The objective of this experiment was to determine the effects of a social partner on calf performance and behavior. We predicted that, because of the effects of social facilitation, pair-housed calves would eat more solid feed and gain more weight during the milk-feeding period. We also predicted that pair-housed calves would show a reduced distress response and growth check at weaning from milk. Finally, we predicted that pair-housed calves would ingest more starter and consequently gain more weight than the single-housed calves when all calves were grouped after weaning.

\section{MATERIALS AND METHODS}

This study was conducted at the University of British Columbia's Dairy Education and Research Centre, Agassiz, Canada, and was approved by the UBC Animal Care Committee. Twenty-seven Holstein dairy heifers were allocated to individual $(\mathrm{n}=9)$ or pair housing ( $\mathrm{n}=9$ pairs) and balanced by birth weight (mean \pm SD; individual $46.8 \pm 4.3 \mathrm{~kg}$ vs. pair $47.1 \pm 4.1 \mathrm{~kg}$ ). Calves were separated from their dams and fed colostrum within $12 \mathrm{~h}$ of birth. Blood samples were collected from the jugular vein $24 \mathrm{~h}$ after the first feeding of colostrum, and serum was analyzed using a Reichert AR
200 digital hand-held refractometer (Reichert, Depew, $\mathrm{NY}$ ). Only calves having a serum protein level $>5.5 \mathrm{~g} /$ $\mathrm{dL}$ were included in the study.

During the first $4 \mathrm{~d}$ of life, calves were housed individually in sawdust-bedded pens measuring $1.2 \mathrm{~m} \times$ $2.0 \mathrm{~m}$ and were fed a maximum of $6 \mathrm{~L}$ of whole milk/ feeding per calf twice daily. Calves were sedated and dehorned at $4 \mathrm{~d}$ of age using caustic paste. When calves were $5 \mathrm{~d}$ old, they were subjected to a general clinical health examination. Only clinically healthy calves were included in this study.

\section{Feed}

During milk feeding, calves had ad libitum access to pasteurized whole milk (a mixture of saleable and nonsaleable milk) provided twice a day for $2 \mathrm{~h}$ at 0700 and 1900 h. Calves had free access to water, orchard grass hay, and pelleted calf starter over the entire experimental period (Unifeed Calf Tex, Chilliwack, BC, Canada). Milk samples were collected twice a week and analyzed separately (Pacific Milk Analysis Lab, Chilliwack, BC, Canada). Starter and hay samples were collected daily and pooled weekly for analysis (Cumberland Valley Analytical Services, Maugansville, MD). The chemical composition of the feed provided to the calves over the experimental period is illustrated in Table 1.

\section{Experimental Period: Preweaning (d 1 to 36 ) and Weaning (d 37 to 55)}

Milk was provided via a teat twice a day at ad libitum volumes per 2-h feeding (see von Keyserlingk et

Table 1. Mean $( \pm \mathrm{SD})$ chemical composition of starter, grass hay, and milk

\begin{tabular}{|c|c|c|c|}
\hline Parameter & Starter ${ }^{1}$ & $\mathrm{Hay}^{2}$ & Milk $^{3}$ \\
\hline DM (\%) & $89.5 \pm 0.62$ & $87.4 \pm 3.1$ & $\mathrm{ND}^{4}$ \\
\hline $\mathrm{CP}(\%$ of $\mathrm{DM})$ & $20.67 \pm 0.21$ & $17.7 \pm 2.34$ & $3.2 \pm 0.25$ \\
\hline $\mathrm{NDF}(\%$ of $\mathrm{DM})$ & $18.6 \pm 1.31$ & $62.4 \pm 2.66$ & ND \\
\hline $\operatorname{ADF}(\%$ of $\mathrm{DM})$ & $11.0 \pm 0.35$ & $34.8 \pm 1.59$ & ND \\
\hline Fat $(\%)$ & ND & ND & $3.72 \pm 0.24$ \\
\hline Ash $(\%$ of DM) & $7.63 \pm 0.4$ & $9.1 \pm 1.1$ & ND \\
\hline Lactose (\%) & ND & ND & $4.2 \pm 0.06$ \\
\hline $\mathrm{Ca}(\%$ of $\mathrm{DM})$ & $1.23 \pm 0.03$ & $0.37 \pm 0.09$ & ND \\
\hline $\mathrm{Cu}(\mathrm{mg} / \mathrm{kg})$ & $53.3 \pm 8.4$ & $21.3 \pm 33.6$ & ND \\
\hline $\mathrm{P}(\%$ of $\mathrm{DM})$ & $0.68 \pm 0.01$ & $0.29 \pm 0.05$ & ND \\
\hline $\operatorname{Mn}(\mathrm{mg} / \mathrm{kg})$ & $112.3 \pm 2.5$ & $86.3 \pm 0.38$ & ND \\
\hline $\mathrm{K}(\%$ of $\mathrm{DM})$ & $0.99 \pm 0.02$ & $3.32 \pm 0.58$ & ND \\
\hline $\mathrm{Na}(\%$ of $\mathrm{DM})$ & $0.49 \pm 0.06$ & $0.058 \pm 0.05$ & ND \\
\hline $\mathrm{Fe}(\mathrm{mg} / \mathrm{kg})$ & $417.3 \pm 7.1$ & $240.8 \pm 72.4$ & ND \\
\hline $\mathrm{Zn}(\mathrm{mg} / \mathrm{kg})$ & $305.0 \pm 3.6$ & $41.5 \pm 13.7$ & ND \\
\hline $\mathrm{SCC}(\times 1,000 / \mathrm{mL})$ & ND & ND & $857.7 \pm 372.6$ \\
\hline Net energy gain (Mcal/kg) & $1.12 \pm 0.02$ & $0.83 \pm 0.04$ & ND \\
\hline
\end{tabular}

${ }^{1}$ Pelleted starter diet (Unifeed CalfTex, Chilliwack, BC, Canada).

${ }^{2}$ Orchardgrass hay.

${ }^{3}$ Mixture of saleable and nonsaleable whole milk.

${ }^{4} \mathrm{ND}=$ not determined. 
al., 2006). Daily milk intakes were recorded by measuring the amount of milk ingested at each feeding. Daily (24-h) starter and water intakes were determined each morning. The milk feeding equipment was washed and disinfected with a 5,000 ppm hypochloride solution after each feeding. Water and starter buckets were cleaned daily.

Individual pens measured $1.2 \mathrm{~m} \times 2.0 \mathrm{~m}$. Pair-housed calves were provided twice the area $(2.4 \mathrm{~m} \times 2.0 \mathrm{~m})$. Sawdust was added to the pens every other day with the bedding completely replaced and the walls washed once a week. Milk weaning was carried out gradually by dilution with water at a rate of $10 \%$ per feeding over the course of $5 \mathrm{~d}$, beginning in the morning of $\mathrm{d}$ 37. Calves continued to receive water via artificial teats from d 42 to 48 . On d 49, the teats were removed but calves remained in their pens until d 55 with free access to hay, starter, and water provided via buckets. All calves were housed in the same area, and calves were able to hear and see other calves; however, no other type of social contact was possible for the individually housed calves. Each calf had access to its own milk teat, hay rack, water, and starter buckets.

Calves were weighed and their health was checked every other day before the morning feeding. Health checks consisted of 1$)$ diarrhea scoring of calves $(1=$ normal feces; $2=$ plaques but not watery; $3=$ watery and body temperature $<39.5^{\circ} \mathrm{C} ; 4=$ watery and body temperature $\geq 39.5^{\circ} \mathrm{C}$ ), and 2) clinical examination of the respiratory system (absence of nasal discharges and pathological sounds of pulmonary infection during auscultation). When calves were diagnosed as ill, they were treated according to current veterinary practices adopted on farm (e.g., by administering antibiotic drugs and electrolytic solutions).

The number of vocalizations was monitored by direct observations from d 42 to 55 . Calves were observed for $1 \mathrm{~h}$ during the morning and evening feedings, totaling $2 \mathrm{~h} / \mathrm{d}$ of observations.

\section{Mixing (d 56 to 70)}

On d 56, calves were moved to a group pen and monitored for $15 \mathrm{~d}$. The experiment ended on d 70. There were 6 replications of the mixing period and each group consisted of 6 calves: 3 older calves and 3 focal calves from this study (1 previously housed as an individual and 2 from a single pair). The group pen measured 7.0 $\mathrm{m} \times 5.0 \mathrm{~m}$ and was equipped for free access to water and hay (intakes not measured). A CF1000CS-Combi automatic feeder (DeLaval, Tumba, Sweden) measured intakes of calf starter. Visits to the starter feeder were defined as beginning when the calf's entire body was inside the feeder allowing automatic recognition of calf's transponder. Body weight was recorded automatically at every visit to the drinker. Sawdust was added once a week to the group pen, and pens were cleaned when the group was moved on $\mathrm{d} 70$.

\section{Statistical Analyses}

Milk Feeding and Weaning Periods. The effect of housing (single versus pair) on milk intake, starter intake, water intake, BW, and vocalizations was tested by obtaining the mean value of the pen (i.e., based on a single calf per pen for the individual treatment and the mean of the 2 calves per pen in the pair treatment), on each experimental day. These data were normally distributed. Because delivery of the liquid diet varied during weaning, we separated the analysis for the preweaning and weaning phases into 4 periods: 1 ) milk feeding (from d 1 to 36), 2) milk dilution (from d 37 to 41), 3) water via teat (from d 42 to 48), and 4) no liquid via teat (from d 49 to 55). Vocalizations were analyzed for periods 3 and 4 because they were recorded only from d 42 to 55 . The effect of treatment (1 df) was tested separately for each period and each variable using PROC MIXED in SAS (version 9.1, SAS Institute Inc., Cary, NC) with 16 error df. Least squares means and standard errors were determined using the LSMEANS statement in the MIXED procedure.

Mixing Period. The effect of previous housing type at grouping (1 df) on the average time spent at the starter feeder, number of visits to the starter feeder, starter intake, and growth rate was tested by obtaining the daily mean value per calf (or pair for the previously paired calves). The effect of treatment was tested using PROC MIXED of SAS (version 9.1, SAS Institute Inc.) with 10 error df. Least squares means and standard errors were determined using the LSMEANS statement in the MIXED procedure. All data were normally distributed. The analysis for growth rate was carried out in two ways. The analysis of weight gain over the entire 15 -d period did not include the effect of day. Growth check was greatest during the first $2 \mathrm{~d}$ after mixing, so we analyzed changes in BW over this period including day in the model.

\section{RESULTS}

\section{Milk and Water Intakes via Teat}

Milk intake increased over the preweaning period (Figure 1). For example, intake increased from (mean \pm SD) $7.3 \pm 1.6 \mathrm{~kg} /$ calf on d 2 to $10.7 \pm 1.7 \mathrm{~kg} /$ calf on d 36. Average intakes of milk were similar in pair- and single-housed calves (mean $\pm \mathrm{SD} ; 9.6 \pm 1.8 \mathrm{~kg} / \mathrm{d} /$ calf; $P=0.36)$, even at the end of the milk-feeding period 


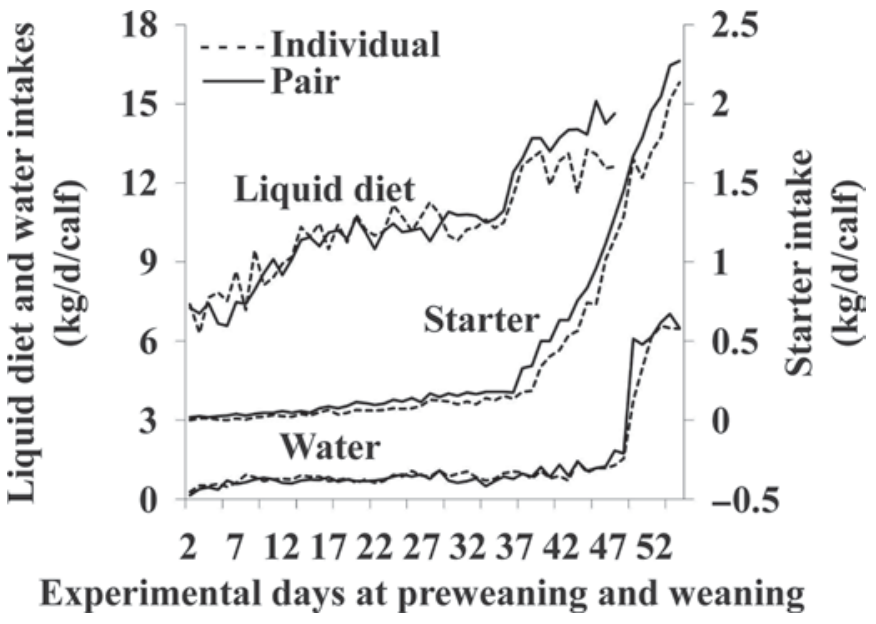

Figure 1. Mean intake of starter $(\mathrm{kg} / \mathrm{d}$ per calf), liquid diet $(\mathrm{kg} / \mathrm{d}$ per calf; milk, diluted milk, and water provided via teat), and water $(\mathrm{kg} / \mathrm{d}$ per calf; provided via bucket) for calves housed in pairs $(\mathrm{n}=9$ pairs) or individually ( $\mathrm{n}=9$ calves) during the milk feeding ( $\mathrm{d} 1$ to 36 ) and weaning (d 37 to 55 ) periods.

(mean $\pm \mathrm{SD} ; 12.6 \pm 3.5 \mathrm{~kg} /$ calf on d 41). When water was provided via teat there was a tendency for pairhoused calves to ingest more water (15.2 vs. $12.7 \pm$ $0.5 \mathrm{~kg} / \mathrm{d} /$ calf; $P=0.05$ ) compared with individually housed calves.

\section{Water Intake via Bucket}

During the preweaning period, water intake increased gradually over time for both single-and pair-housed calves (mean $\pm \mathrm{SD} ; 0.2 \pm 0.1 \mathrm{~kg} /$ calf on $\mathrm{d} 2$ to 0.9 $\pm 0.7 \mathrm{~kg} /$ calf on $\mathrm{d} 36$; Figure 1) with no difference in intakes between treatment groups (mean $\pm \mathrm{SD}$; $0.7 \pm$ $0.5 \mathrm{~kg} / \mathrm{d}$ per calf; $P=0.54$ ). Water intakes also did not differ during the dilution phase (mean $\pm \mathrm{SD} ; 0.93 \pm 0.6$ $\mathrm{kg} / \mathrm{d}$ per calf; $P=0.99$ ), but intakes were higher in the pair-housed calves when only water was available from the teat (1.7 vs. $1.0 \pm 0.16 \mathrm{~kg} / \mathrm{d}$ per calf, respectively; $P=0.03)$. When the teat was removed, water intake via buckets was again similar between the 2 treatments (mean $\pm \mathrm{SD} ; 5.5 \pm 1.6 \mathrm{~kg} / \mathrm{d}$ per calf; $P=0.10$ ).

\section{Starter Intake}

Starter intake over the preweaning period was higher for pair-housed calves (93 vs. $59 \pm 11 \mathrm{~g} / \mathrm{d}$ per calf; $P$ $=0.04)$. Starter intake increased with calf age, from (mean $\pm \mathrm{SD}$ ) $25 \pm 30 \mathrm{~g} / \mathrm{d}$ per calf during the first 2 wk to $145 \pm 93 \mathrm{~g} / \mathrm{d}$ per calf during the last week of the preweaning period. Starter intake during milk dilution averaged (mean $\pm \mathrm{SD}) 0.3 \pm 0.2 \mathrm{~kg} / \mathrm{d}$ per calf $(P=$ 0.22 ) and was highly variable, ranging from $150 \pm 100$ $\mathrm{g} /$ calf on d 37 to $450 \pm 300 \mathrm{~g} /$ calf on d 41 . When only water was provided via teat, starter intakes averaged $($ mean $\pm \mathrm{SD}) 0.8 \pm 0.3 \mathrm{~kg} / \mathrm{d}$ per calf $(P=0.11)$ over the entire period, ranging from (mean $\pm \mathrm{SD}$ ) $0.5 \pm 0.3$ $\mathrm{kg} /$ calf on d 42 to $1.2 \pm 0.4 \mathrm{~kg} /$ calf on d 48 . When the teat was removed, calves consumed an average (mean $\pm \mathrm{SD})$ of $1.9 \pm 0.4 \mathrm{~kg} / \mathrm{d}$ per calf of starter $(P=0.2)$, ranging from (mean $\pm \mathrm{SD}$ ) $1.4 \pm 0.4 \mathrm{~kg} /$ calf on d 49 to $2.3 \pm 0.5 \mathrm{~kg} /$ calf on d 55 .

\section{Weight Gain}

There was no difference in BW between the 2 treatment groups during the preweaning and weaning periods. Calves averaged (mean $\pm \mathrm{SD}$ ) $61.0 \pm 4.7 \mathrm{~kg} /$ calf during the milk feeding period $(P=0.73), 79.7 \pm 6.5$ $\mathrm{kg} /$ calf during the milk dilution period $(P=0.88), 82.0$ $\pm 6.0 \mathrm{~kg} /$ calf $(P=0.48)$ when water was provided via teat, and $88.3 \pm 6.7 \mathrm{~kg} /$ calf $(P=0.43)$ after the teat was removed.

\section{Number of Vocalizations}

Individually housed calves vocalized 3 times more than did pair-housed calves over the period from d 42 until d 48 (7.6 vs. $2.1 \pm 0.7$ calls/calf per 2 -h period; $P<0.001$; Figure 2). The number of vocalizations remained high on the days after the removal of the milk teat (d 49 to 55) with individually housed calves again vocalizing more often than pair-housed calves (75.7 vs. $29.4 \pm 6.0$ calls/calf; $P<0.001)$.

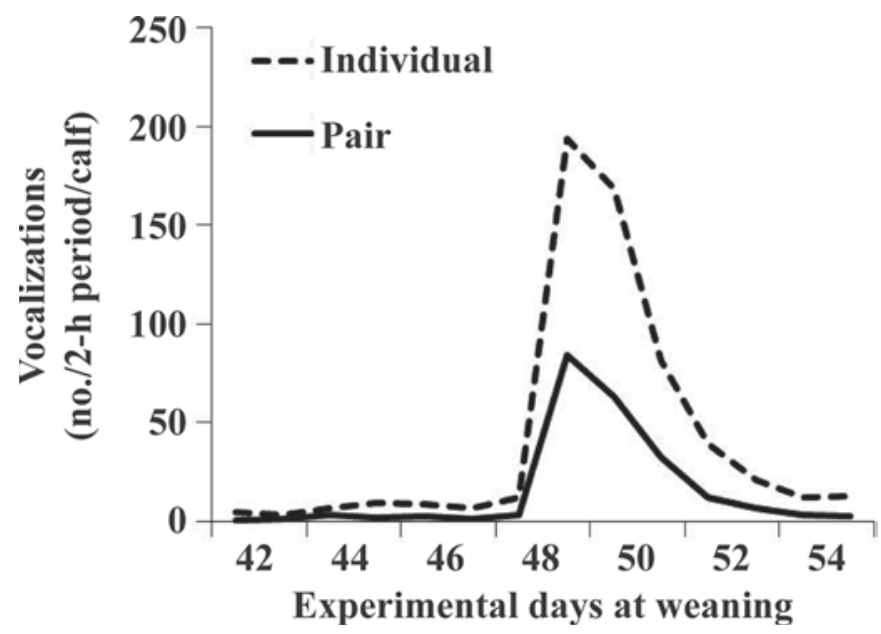

Figure 2. Mean number of vocalizations (2-h period/d per calf) for pair-housed ( $\mathrm{n}=9$ pairs) and individually housed ( $\mathrm{n}=9$ calves) calves during weaning (d 42 to 55 ). 


\section{Mixing Period}

The latency for calves to first visit the starter feeder was shorter for calves that were previously pair-housed versus individually housed (mean $\pm \mathrm{SD} ; 9.1 \pm 2.6 \mathrm{~h}$ vs. $49.5 \pm 4.1 \mathrm{~h} /$ calf $)$. Paired calves spent more time at the feeder $(87.8 \pm 2.5$ vs. $65.3 \pm 2.9 \mathrm{~min} / \mathrm{d}$ per calf; $P<0.001$; Figure $3 \mathrm{~A}$ ), visited the feeder more often (41.6 \pm 3.0 vs. $26.4 \pm 3.3$ visits/d per calf; $P=$ 0.008; Figure 3B), and consumed more starter (3.46 vs. $2.3 \pm 0.2 \mathrm{~kg} / \mathrm{d}$ per calf; $P=0.002$; Figure $3 \mathrm{C}$ ). Pair-housed calves began eating starter on $\mathrm{d} 1$, whereas single-housed calves consumed no starter on d 1 or 2 . Starter intake of pair-housed calves was (mean \pm SD) $1.2 \pm 0.6 \mathrm{~kg} /$ calf on $\mathrm{d} 1$ and $2.4 \pm 0.5 \mathrm{~kg} /$ calf on $\mathrm{d} 2$. On d 3, starter intake averaged (mean \pm SD) $3.0 \pm$ $0.7 \mathrm{~kg} /$ calf for pair-housed and $0.4 \pm 0.9 \mathrm{~kg} /$ calf for single-housed calves.

Weight gains at mixing were higher for paired than for individually housed calves at d $2(0.5$ vs. $-2.4 \pm 0.3$ $\mathrm{kg} /$ calf; $P<0.004)$ and d $3(0.9$ vs. $-0.9 \pm 0.3 \mathrm{~kg} /$ calf; $P=0.02)$. Over the remainder of the mixing period, there was no effect of treatment on weight gain, with calves gaining, on average (mean $\pm \mathrm{SD}$ ), $0.5 \pm 0.21$ $\mathrm{kg} / \mathrm{d}$ per calf $(P=0.7$; Figure $3 \mathrm{D})$.

\section{DISCUSSION}

Pair housing did not influence weight gains during the milk feeding and weaning periods in our study. Previous studies that reported increased weight gains for group-housed calves (e.g., Chua et al., 2002; Xicatto et al., 2002; Tapki, 2007) varied in management practices and experimental design (e.g., feeding frequency, number of animals, milk volume, and duration of the feeding period), so readers should interpret differences among these studies with care.

Pair-housed calves ingested more starter during the preweaning period than did individually housed calves, but intakes in both treatments were within the range

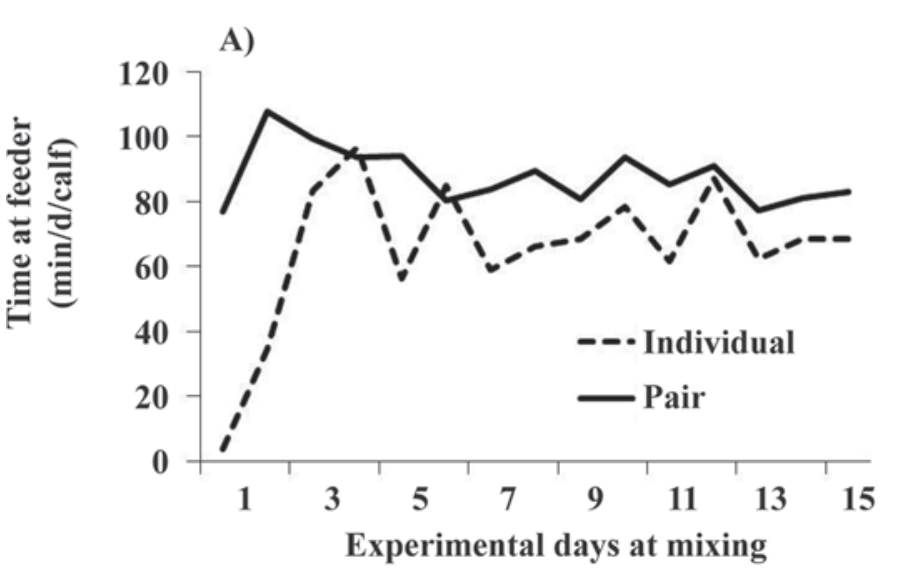

B)

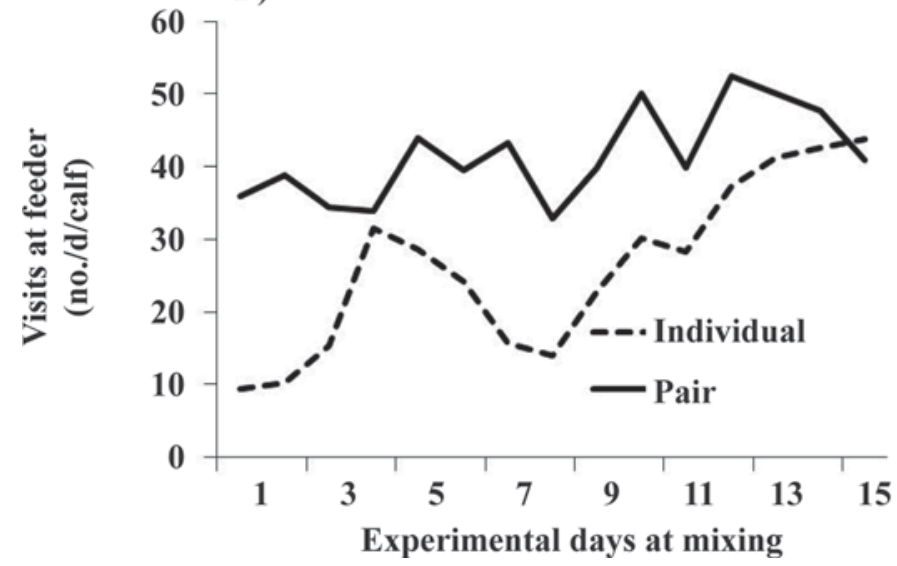

C)

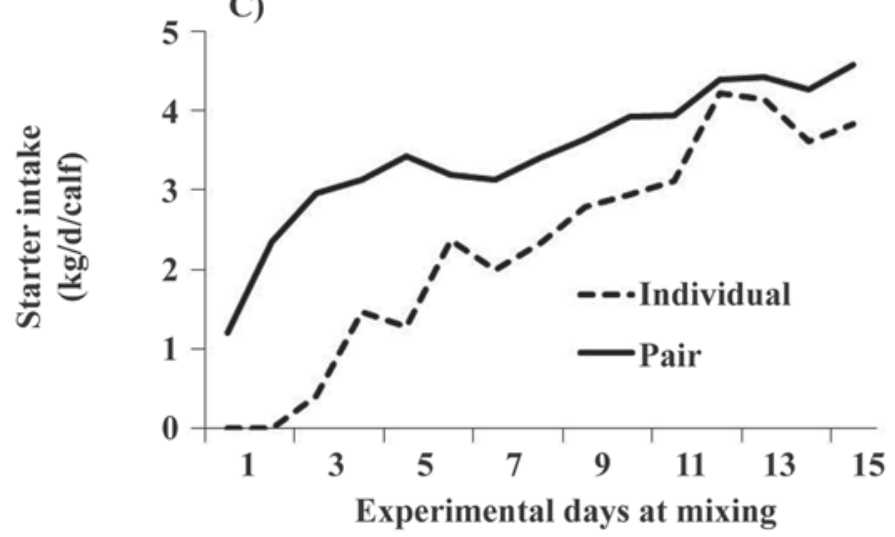

D)

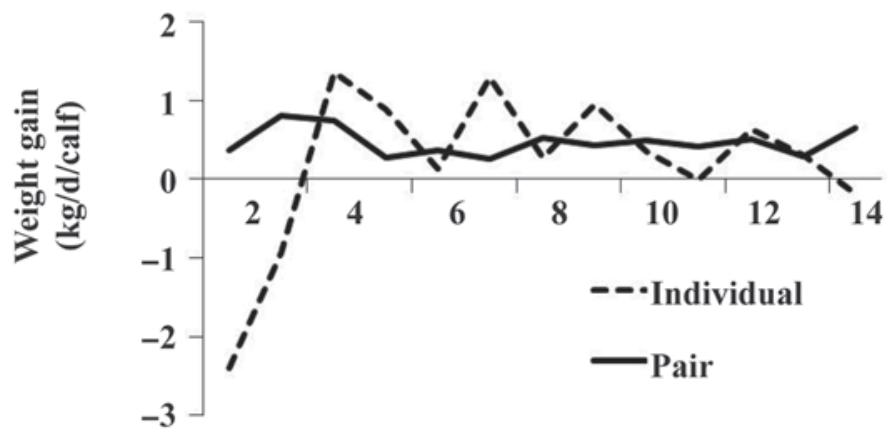

Experimental days at mixing

Figure 3. The effect of mixing ( $\mathrm{d} 56$ to 70$)$ for pair ( $\mathrm{n}=6$ pairs) and individually ( $\mathrm{n}=6$ calves) housed dairy calves on $\mathrm{A}$ ) mean duration of visits to the starter feeder (min/d per calf); B) mean number of visits to the starter feeder (no./d per calf); C) mean starter intake/visit (kg/d per calf); and D) mean growth rate $(\mathrm{kg} / \mathrm{d}$ per calf). 
previously reported for calves fed higher milk volumes (e.g., Jasper and Weary, 2002). The higher starter intake in the pair-housed calves may be attributed to social facilitation. Although we only noted increased starter intake in the pair-housed calves during the milkfeeding period, others (e.g., Babu et al., 2004; Hepola et al., 2006) have reported similar effects over a longer feeding period.

At weaning, individually housed calves showed a stronger vocal response than did paired calves. The number of vocalizations peaked on d 49, when the teat was no longer available. Stronger vocal responses to weaning have been linked to the lack of access to the feeding system, rather than the lack of milk per se (Budzynska and Weary, 2008). The reduced responses of the pair-housed calves may be because of social buffering effects described in other species (see Kikusui et al., 2006); to our knowledge, this is the first evidence of social buffering in response to weaning distress in cattle.

The results of this study suggest that the paired calves may have higher behavioral flexibility; that is, the ability to modify behavior in response to a changing environment such as mixing with unfamiliar calves in a novel environment. Paired calves spent more time at the feeder, visited the feeder more often, and started ingesting concentrate from the computerized starter feeder more rapidly than did individually housed calves, such that the paired calves ingested more solid feed and gained more weight. The differences in feeding behavior at mixing may be explained by the socially inexperienced single-housed calves having to learn how to use the feeder as well as learning how to cope with conspecifics. In contrast, the pair-housed calves were able to draw on previous social experiences enabling them to observe and imitate the behavior of the calves in the group that had previous experience with the feeding system. Differences in response may also have been because of cognitive differences due to early social experiences of paired calves. Social isolation in rats seems to disrupt brain development, resulting in behavioral and neurochemical changes (Schrijver and Würbel, 2001) that reduce measures of cognitive performance. Studies are now required to understand the role that different housing systems may play in affecting the social and cognitive development of dairy calves.

\section{CONCLUSIONS}

Pair housing during the milk-feeding period reduced behavioral responses to weaning and improved performance of calves grouped after weaning.

\section{ACKNOWLEDGMENTS}

The authors thank the members of the Animal Welfare Program, especially those that helped with the study including Alie De Haaij and Angela Greter. Andreia De Paula Vieira was sponsored by the Capes Foundation of the Ministry of Education of Brazil. This research is supported by an NSERC Discovery grant to Daniel M. Weary, and by Canada's Natural Sciences and Engineering Research Council (Ottawa, ON, Canada) Industrial Research Chair Program with industry contributions from the Dairy Farmers of Canada (Ottawa, ON, Canada), Westgen Endowment Fund (Milner, BC, Canada), Pfizer Animal Health (Kirkland, QC, Canada), BC Cattle Industry Development Fund (Kamloops, BC, Canada), the BC Milk Producers (Burnaby, BC, Canada), BC Dairy Foundation (Burnaby, BC, Canada), BC Dairy Education and Research Association (Abbotsford, BC, Canada), and Alberta Milk (Edmonton, AB, Canada).

\section{REFERENCES}

Babu, L. K., H. N. Pandey, and A. Sahoo. 2004. Effect of individual versus group rearing on ethological and physiological responses of crossbred calves. Appl. Anim. Behav. Sci. 87:177-191.

Bartolomucci, A. 2007. Social stress, immune functions and disease in rodents. Front. Neuroendocrinol. 28:28-49.

Budzynska, M., and D. M. Weary. 2008. Weaning distress in dairy calves: Effects of alternative weaning procedures. Appl. Anim. Behav. Sci. 112:33-39.

Chua, B., E. Coenen, J. van Delen, and D. M. Weary. 2002. Effects of pair versus individual housing on the behavior and performance of dairy calves. J. Dairy Sci. 85:360-364.

Davitz, J., and D. J. Mason. 1955. Socially facilitated reduction of fear response in rats. J. Comp. Physiol. Psychol. 47:941-947.

Færevik, G., I. L. Andersen, M. B. Jensen, and K. E. Bøe. 2007. Increased group size reduces conflicts and strengthens the preference for familiar group mates in dairy calves (Bos taurus). Appl. Anim. Behav. Sci. 108:215-228.

Hepola, H., L. Hänninen, P. Pursiainen, V.-M. Tuure, L. SyrjäläQvist, M. Pyykkönen, and H. Saloniemi. 2006. Feed intake and oral behavior of dairy calves housed individually or in groups in warm or cold buildings. Livest. Sci. 105:94-104.

Hsia, L. C., and D. G. M. Wood-Gush. 1984. Social facilitation in the feeding behavior of pigs and the effect of rank. Appl. Anim. Ethol. $11: 265-270$

Jasper, J., and D. M. Weary. 2002. Effects of ad libitum milk intake on dairy calves. J. Dairy Sci. 85:3054-3058.

Jensen, M. B., L. Munksgaard, L. Mogensen, and C. C. Krohn. 1999. Effects of housing in different social environments on open-field and social responses of female dairy calves. Acta Agric. Scand. A Anim. Sci. 49:113-120.

Jensen, M. B., K. S. Vestergaard, C. C. Krohn, and L. Munksgaard. 1997. Effect of single versus group housing and space allowance on responses of calves during open-field tests. Appl. Anim. Behav. Sci. 54:109-121.

Kikusui, T., J. T. Winslow, and Y. Mori. 2006. Social buffering: Relief from stress and anxiety. Phil. Trans. R. Soc. B 361:2215-2228.

Morrison, B. J., and W. F. Hill. 1967. Social facilitation reduction of the fear response in rats raised in groups or in isolation. J. Comp. Physiol. Psychol. 63:71-76. 
Napolitano, F., G. Annicchiarico, M. Caroprese, G. De Rosa, L. Taibi, and A. Sevi. 2003. Lambs prevented from suckling their mothers display behavioral, immune and endocrine disturbances. Physiol. Behav. 78:81-89.

Panksepp, J. 1998. Loneliness and the social bond. Pages 261-279 in Affective Neuroscience: The Foundations of Human and Animal Emotions. J. Panksepp, ed. Oxford University Press, New York, NY.

Schrijver, N. C. A., and H. Würbel. 2001. Early social deprivation disrupts attentional, but not affective, shifts in rats. Behav. Neurosci. 115:437-442.

Sharp, J. L., T. G. Zammit, T. A. Azar, and D. M. Lawson. 2002. Stress-like responses to common procedures in male rats housed alone or with other rats. Contemp. Top. Lab. Anim. Sci. 41:8 14.

Tapki, I. 2007. Effects of individual or combined housing systems on behavioral and growth responses of dairy calves. Acta Agric. Scand. 57:55-60.

Taylor, G. T. 1981. Fear and affiliation in domesticated male rats. J. Comp. Physiol. Psychol. 95:685-693.
Terré, M., A. Bach, and M. Devant. 2006. Performance and behaviour of calves reared in groups or individually following an enhancedgrowth feeding programme. J. Dairy Res. 73:480-486.

Veissier, I., V. Gesmier, P. Le Neindre, J. Y. Gautier, and G. Bertrand. 1994. The effects of rearing in individual crates on subsequent social behaviour of veal calves. Appl. Anim. Behav. Sci. 41:199 210.

von Keyserlingk, M. A. G., F. Wolf, M. Hotzel, and D. M. Weary. 2006. Effects of continuous versus periodic milk availability on behavior and performance of dairy calves. J. Dairy Sci. 89:2126-2131.

Wattanakul, W., H. L. Bulman, and S. A. Edwards. 2005. The effect of creep feed presentation method on feeding behaviour, intake and performance of suckling piglets. Appl. Anim. Behav. Sci. 92:27-36.

Weary, D. M., J. Jasper, and M. Hötzel. 2008. Understanding weaning distress. Appl. Anim. Behav. Sci. 110:24-41.

Xicatto, G., A. Trocino, P. I. Queaque, A. Sartori, and A. Carazzolo. 2002. Rearing veal calves with respect to animal welfare: Effects of group housing and solid feed supplementation on growth, performance and meat quality. Livest. Prod. Sci. 75:269-280. 